\title{
Cyanate Specifically Inhibits Arginine Biosynthesis in Escherichia coli K12: a Case of By-product Inhibition?
}

\author{
By MICHEL GUILLOTON* AND FRANCIS KARST \\ Laboratoire de Biochimie et Génétique des Microorganismes, JE CNRS 034620, \\ Université de Poitiers, 40 Avenue du Recteur Pineau, 86022 Poitiers Cédex, France
}

(Received 14 July 1986; revised 17 September 1986)

\begin{abstract}
Growth of Escherichia coli $\mathrm{K} 12$ cultivated in minimal medium was strongly inhibited by $2 \mathrm{~mm}-$ cyanate. This inhibition could be specifically reversed by arginine. Citrulline (but not ornithine, $N$ - $\alpha$-acetylornithine or $N$-acetylglutamate) could also restore a normal growth rate. Since growth inhibition by cyanate was followed by an accumulation of ornithine within the cell it was concluded that cyanate specifically inhibits the formation of citrulline from ornithine. The effect of cyanate on the growth of defined strains was consistent with a specific inhibition of carbamoylphosphate synthase. A kinetic study of carbamoylphosphate synthase and ornithine carbamoyltransferase in vitro supported this conclusion. Since carbamoylphosphate is probably the only source of endogenous cyanate it is postulated that carbamoylphosphate synthase activity can be regulated by cyanate resulting from the dissociation of carbamoylphosphate in metabolic circumstances leading to its overproduction.
\end{abstract}

\section{INTRODUCTION}

The toxicity of cyanate for cells and organisms has been known for a long time. Following the cytological studies of Dustin (1947) the toxicity of cyanate for biological systems was described by Schütz (1949). Poisoning effects of cyanate were described in plants, animals and humans; its toxicity for micro-organisms was reported by Taussig (1960). So far, the effect of cyanate on proteins and enzymes in vitro has been characterized by an apparent lack of specificity. It is consequently not known whether the effects observed in vivo could be directed towards more specific targets at the molecular level.

Cyanate is a well known carbamoylating agent which reacts through isocyanic acid with nucleophilic groups, especially with amino (Stark, 1965; Williams \& Jencks, 1974) and thiol groups (Stark, 1964). Many proteins and enzymes have been shown to undergo structural and functional alterations after carbamoylation mediated by cyanate. Some enzymes are inactivated by a specific reaction with a group essential for catalysis, e.g. papain (Sluyterman, 1967), bovine glutamate dehydrogenase (Veronese et al., 1972), tobacco ribulose-1,5-bisphosphate carboxylase (Chollet \& Anderson, 1978), and carbamoylphosphate synthase from Escherichia coli (Anderson \& Carlson, 1975). Cyanate is also a pseudohalide ion which can form complexes with transition metal ions (Forster \& Goodgame, 1965). Some enzymes are inactivated by cyanate after chelation of a metal ion in the active site, e.g. carbonic anhydrase (Engberg \& Lindskog, 1984), superoxide dismutase (Bertini et al., 1981), and cobalt(II) carboxypeptidase A (Bertini et al., 1985).

This article deals with the effect of cyanate on the physiology of $E$. coli $\mathrm{K} 12$ and more precisely with the specific inhibition of arginine biosynthesis exerted by cyanate.

Abbreviations: ACTase, aspartate carbamoyltransferase; CP, carbamoylphosphate; CPSase, carbamoylphosphate synthase; OCTase, ornithine carbamoyltransferase.

0001-3585 C 1987 SGM 


\section{METHODS}

Bacterial strains. All strains used in the present study were derivatives of Escherichia coli $\mathrm{K} 12$. They are listed in Table 1. BGM $023(\mathrm{cnt} 3)$ is a mutant of strain R5, lacking inducible cyanase (see the preceding paper: Guilloton \& Karst, 1987). BGM 171 is a spontaneous $\arg R$ mutant derived from BGM 023 by selection on 'arginine-free' medium (Novick \& Maas, 1961) supplemented with canavanine according to Maas (1961). BGM 180, which harbours the carB8 deletion, was obtained as follows: a $t h r$ derivative (BGM 167) of BGM 023 was obtained after UV irradiation and penicillin enrichment; this strain was transduced to $\mathrm{Thr}^{+}$by bacteriophage $\mathrm{Pl}$ cultivated on strain CSH 73 (carB8) (Lissens et al., 1980) and strain BGM 180 (cnt3 carB8) was scored as a double $\mathrm{Arg}^{-} \mathrm{Ura}^{-}$ auxotroph among the $\mathrm{Thr}^{+}$transductants. Strain 58161 ( $\mathrm{carB} 8 \mathrm{thr} \mathrm{metB} / \mathrm{pMC} 40 \mathrm{carA}^{+} \mathrm{car} \mathrm{B}^{+}$) was provided to us by Marjolaine Crabeel and André Piérard; this strain harbours the pMC40 recombinant plasmid with the adjacent car $A B$ genes subcloned by insertion into the HindIII site of pBR322. BGM 186 was obtained by transformation of BGM 180 by pMC 40 and selection for $\mathrm{Amp}^{R}$; BGM 186, prototrophic for arginine and uracil, has a specific activity of carbamoylphosphate synthase 13 times greater than strain BGM 023 when cultivated in minimal medium. BGM 209 ( $c n t 3$ carB8) is a spontaneous citrulline-utilizing mutant obtained by plating strain BGM 180 on a solid minimal medium containing L-citrulline $\left(2000 \mu \mathrm{g} \mathrm{ml}^{-1}\right)$, according to Legrain et al. (1976).

Genetic techniques. Generalized transduction mediated by bacteriophage $\mathrm{Pl}$ was performed according to Miller (1972); bacteriophage Plvir was kindly supplied by M. Schwartz (Institut Pasteur, Paris, France). Plasmid pMC40 was isolated from strain $58161 / \mathrm{pMC} 40$ by the small-scale boiling method and transformation experiments were done by the calcium chloride procedure described by Maniatis et al. (1982).

Media and growth conditions. L broth and synthetic A medium described by Miller (1972) were used throughout this study. Bacterial cells were cultivated with shaking in $25 \times 250 \mathrm{~mm}$ test tubes at $37^{\circ} \mathrm{C}$; optical densities (OD) were monitored at $575 \mathrm{~nm}$ directly in the test tubes using a Coleman Junior AII spectrophotometer. OD $_{575}$ was proportional to cell density up to $0 \cdot 6$. For physiological studies, overnight cultures in minimal medium were subcultured in the same medium, grown to mid-exponential phase, then diluted to an $\mathrm{OD}_{575}$ of $0 \cdot 1$, the $\mathrm{pH}$ being adjusted to 7.00. Cells were cultivated to an $\mathrm{OD}_{575}$ of $0 \cdot 2$ before addition of cyanate or other solutions and growth was followed for a further $150 \mathrm{~min}$.

Cyanate assay. Cyanate was assayed by a spectrophotometric method using a reaction with 2-aminobenzoic acid (Guilloton \& Karst, 1985).

Enzyme assays. Carbamoylphosphate synthase (CPSase; EC 6.3.5.5). CPSase activity was measured by coupling carbamoylphosphate (CP) formation with citrulline synthesis in the presence of ornithine and an excess of partially purified ornithine carbamoyltransferase (Piérard \& Wiame, 1964). The assay medium was prepared in $0 \cdot 1 \mathrm{M}$-TES(K) buffer (pH 7.5). Reaction was stopped by addition of cold TCA. After centrifugation of precipitated proteins, citrulline was estimated in the supernatant using a modification of the method of Archibald (1944). Routine assay of CPSase was done with cell-free extracts from cells (mid-exponential phase culture) broken in the cold by ultrasonic treatment in the presence of acid-washed glass beads $(0.12 \mathrm{~mm} \mathrm{diam}$.). The extracts were centrifuged at $15000 \mathrm{~g}$ and filtered at $4{ }^{\circ} \mathrm{C}$ just before enzyme assays through Sephadex G25 columns equilibrated with $0.1 \mathrm{M}-\mathrm{TES}(\mathrm{K})$ buffer $(\mathrm{pH} 7.5)$. Cyanate inhibition of CPSase was studied with a partially purified preparation (specific activity $6 \mathrm{U} \mathrm{mg}^{-1}$ ) obtained from strain BGM 023 according to Anderson et al. (1970): the enzyme fraction obtained after step 6 was treated with solid ammonium sulphate to achieve $65 \%$ saturation and the precipitate was dissolved in $0.2 \mathrm{M}$-potassium phosphate buffer containing $0.5 \mathrm{~mm}$-EDTA (pH 7.9). This enzyme preparation was filtered just before use through a Sephadex G25 column equilibrated with $100 \mathrm{~mm}$ TES(K)/100 mM-KCl buffer (pH 7.5).

Ornithine carbamoyltransferase (OCTase; EC 2.1.3.3). Activity of OCTase in growing cells was routinely assayed on samples of cultures treated with toluene for $20 \mathrm{~min}$ at $37^{\circ} \mathrm{C}$. Activity of OCTase was measured at $37^{\circ} \mathrm{C}$ in a medium (final volume $0.5 \mathrm{ml}$ ) containing $100 \mathrm{mM}$-Tris $/ \mathrm{HCl}$ buffer $(\mathrm{pH} 8), 10 \mathrm{~mm}$ dilithium $\mathrm{CP}$ and $10 \mathrm{mM}-\mathrm{L}$ ornithine. Citrulline was estimated by a modification of the method of Archibald (1944). For the kinetic studies, the assay medium contained, in a volume of $0.95 \mathrm{ml}$, various amounts of L-ornithine and dilithium $\mathrm{CP}$ in a buffer composed of $50 \mathrm{mM}$-Tris/acetate and $50 \mathrm{~mm}-\mathrm{KCl}(\mathrm{pH} 8) . \mathrm{KNCO}$ and zinc acetate solutions were prepared in the same buffer. Test tubes were equilibrated at $37^{\circ} \mathrm{C}$ and the reaction was initiated by adding $50 \mu \mathrm{l}$ of an enzyme preparation diluted in Tris/acetate buffer. The reaction was stopped with $1 \mathrm{ml}$ of the acid mixture described by Prescott \& Jones (1969) and citrulline was estimated according to the same authors, following the optimization procedure of Pastra-Landis et al. (1981). In order to minimize the dissociation of CP, frozen stock solutions were diluted in cold buffer $1 \mathrm{~min}$ before addition to assay mixtures and $\mathrm{CP}$ was added $2 \mathrm{~min}$ before addition of enzyme preparation. Steady-state conditions were observed during the kinetic measurements and enzymically synthesized citrulline did not exceed $10 \%$ of the limiting substrate. The solutions were mixed in the following order: buffer, ornithine, zinc acetate, $\mathrm{CP}$ and enzyme solution, because incubation of enzyme preparations with zinc in the absence of substrates led to a time-dependent decrease of activity. Citrulline formation in the presence of cyanate was corrected for the spontaneous carbamoylation of ornithine by using blanks without enzyme.

A partially purified preparation of OCTase was used as auxiliary enzyme in the assay of CPSase. OCTase from 
Table 1. E. coli strains

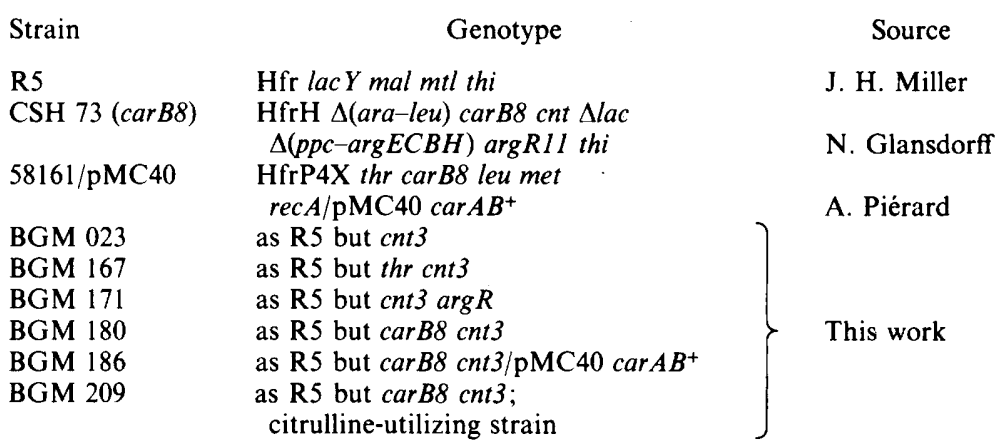

strain CSH 73 ( $\arg R$ carB8) (Lissens et al., 1980) was purified according to Legrain \& Stalon (1976); the preparation consisted of the $40-90 \%$ saturation ammonium sulphate precipitate dissolved in $50 \mathrm{~mm}$-potassium phosphate buffer containing $0.5 \mathrm{~mm}-\mathrm{MgEDTA}(\mathrm{pH} \mathrm{7.5)}$ and dialysed overnight against the same buffer. Such preparations contained at least 30000 units $\mathrm{ml}^{-1}$ and were free of CPSase activity.

Aspartate carbamoyltransferase (ACTase; EC 2.1.3.2). ACTase activity was estimated according to Gerhart \& Pardee (1962). Carbamoylaspartate values were corrected in each assay for the spontaneous carbamoylation of aspartate by cyanate introduced in the assay medium or originating from dissociation of CP.

Enzyme units. One unit of enzyme activity is the amount of enzyme which catalyses the formation of $1 \mu \mathrm{mol}$ product $h^{-1}$. Specific activities are expressed as units (mg protein) $)^{-1}$. Protein in cell extracts was estimated by the biuret method; protein in cell cultures was estimated from $\mathrm{OD}_{575}$ measurements ( $\operatorname{an} \mathrm{OD}_{575}$ of 0.5 corresponded to $0.17 \mathrm{mg}$ protein $\mathrm{ml}^{-1}$ ).

\section{RESULTS}

\section{Nature of the metabolic step blocked by cyanate}

We observed that growth of $E$. coli was inhibited by cyanate more strongly in minimal medium that in L broth (see the preceding paper: Guilloton \& Karst, 1987). This different behaviour could be due to the presence in $\mathrm{L}$ broth of molecules which specifically prevent cyanate inhibition. In a preliminary study we analysed the effects of various metabolites (amino acids, purines and pyrimidines) on this growth inhibition on solid minimal medium supplemented with cyanate. We found that growth was restored specifically by arginine.

Fig. 1 shows that arginine allowed strain R5 to grow at a fairly normal rate after addition of $2 \mathrm{mM}-\mathrm{KNCO}$; this concentration of cyanate strongly inhibits cell growth and cyanase synthesis in non-supplemented minimal medium (Guilloton \& Karst, 1987). Arginine could be replaced by citrulline but not by ornithine, $N$ - $\alpha$-acetylornithine or $N$-acetylglutamate. By means of automated amino acid analysis we observed that the growth inhibition effected by 2 mM-cyanate induced a very large increase in the cellular ornithine pool. Cyanate inhibition was thus suspected to be due to a specific inhibition of the formation of citrulline from ornithine. However, OCTase activity was found to be insensitive to cyanate in vitro (see below). The effect of cyanate on the physiology of $E$. coli had therefore to be understood on the basis of other metabolic interferences such as a decreased availability of CP.

The production of $\mathrm{CP}$ for the arginine and pyrimidine biosynthetic pathways in $E$. coli is achieved by a single CPSase (Fig. 2). This enzyme is encoded by the two adjacent genes, car $A$ and $\operatorname{car} B$ (Mergeay et al., 1974), which form an operon. Although mutations in the $\operatorname{car} A B$ locus generally lead to a double auxotrophy for arginine and uracil, some CPSase mutants behave as arginine bradytrophs (Mergeay et al., 1974) or auxotrophs (Bolivar et al., 1976). Such mutants have also been described in $E$. coli $\mathrm{B} / \mathrm{r}$ (Abd el al et al., 1969) and in Salmonella typhimurium (Abd el al et al., 1978). It was also reported that arginine bradytrophy could be a consequence of mutations in genes whose expression is required for CPSase synthesis (Bussey \& Ingraham, 1982; Neuhard et al., 1982). On the other hand CPSase from E. coli can te inhibited in vitro by 


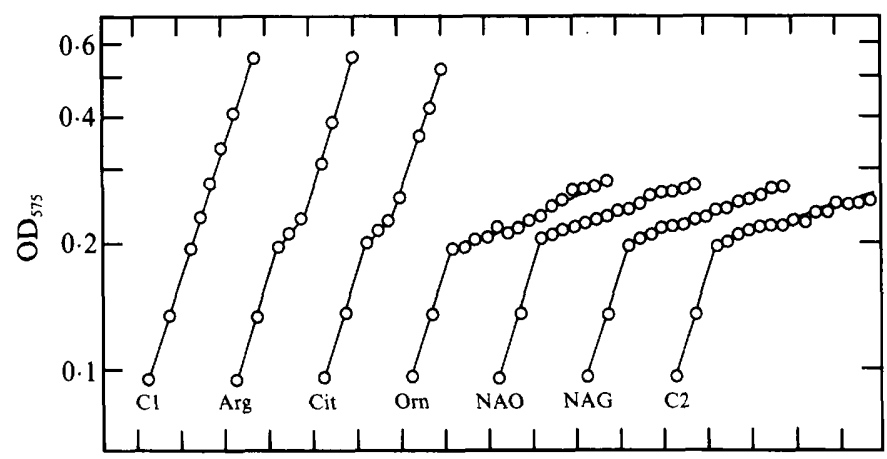

Time (1 scale division $=1 \mathrm{~h}$ )

Fig. 1. Effect of $2 \mathrm{mM}$-cyanate on growth of strain R5, and influence of arginine and intermediates of arginine biosynthesis. Overnight cultures in minimal medium were subcultured as described in Methods. KNCO (final concn $2 \mathrm{mM}$ ) and metabolites (final concn $20 \mu \mathrm{g} \mathrm{ml}^{-1}$ ) were added to the cultures when the $\mathrm{OD}_{575}$ reached $0 \cdot 2$. Arg, arginine hydrochloride; Cit, citrulline; Orn, ornithine hydrochloride; NAO, $N$ - $\alpha$-acetylornithine; NAG, $N$-acetylglutamic acid. $\mathrm{Cl}$ and $\mathrm{C} 2$ are controls which received no cyanate and $2 \mathrm{~mm}$-cyanate, respectively. The cultures that received Arg and Cit showed a lag of 30 min during which cyanate was completely hydrolysed; added cyanate was not hydrolysed in the other cultures.

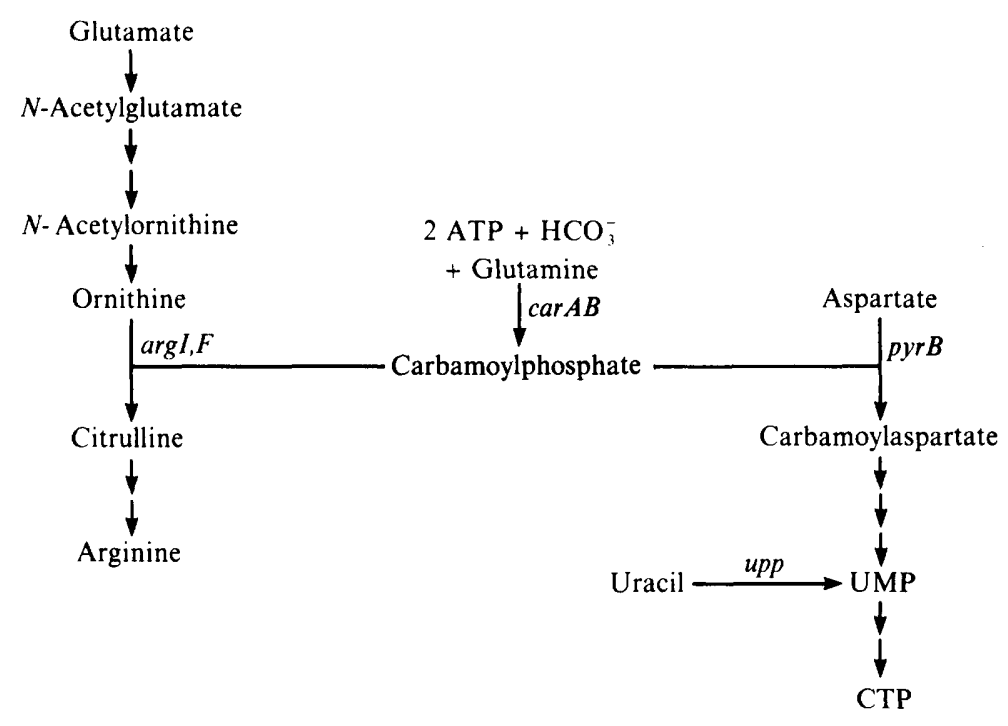

Fig. 2. Biosynthetic pathways of arginine and pyrimidines in E. coli. The relevant genes and enzymes are shown. The enzymes are identified by the genetic symbols of the corresponding structural genes as follows: $\operatorname{car} A B$, carbamoylphosphate synthase (EC 6.3.5.5); $\arg I, F$, ornithine carbamoyltransferase (EC 2.1.3.3); pyrB, aspartate carbamoyltransferase (EC 2.1.3.2); upp, UMP pyrophosphorylase (EC 2.4.2.9).

cyanate (Anderson et al., 1973). Cyanate reacts specifically with a SH group required for glutamine binding and deamidation (Anderson \& Carlson, 1975). It was thus of interest to investigate the interaction of cyanate with arginine and pyrimidine biosynthetic pathways.

Effect of cyanate, arginine and uracil on the physiology of strain BGM 023

Mutant strain BGM 023 (cnt3) was chosen to study the effect of cyanate on cell physiology. This strain (derived from strain R5) lacks inducible cyanase and thus does not hydrolyse added cyanate. Fig. 3 shows the effects of cyanate (1 and $2 \mathrm{mM}$ ) on growth of strain BGM 023 and its 


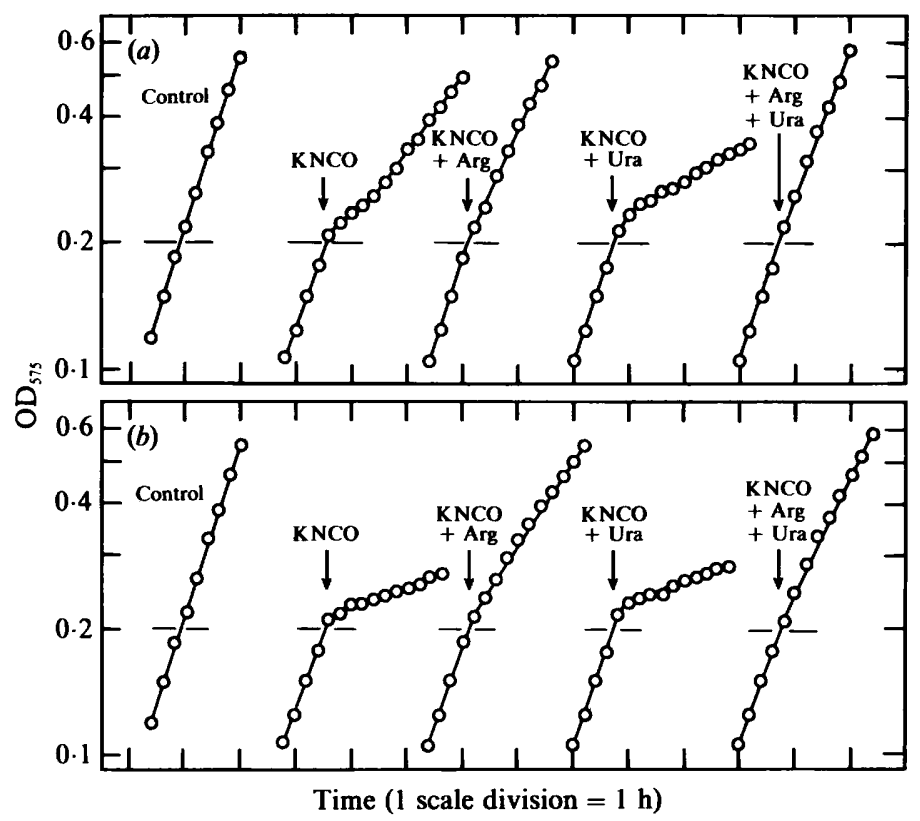

Fig. 3. Effect of cyanate, arginine and uracil on growth of strain BGM 023. An overnight culture in minimal medium was diluted in the same medium and cultured as described in Methods. KNCO ( $1 \mathrm{mM}$, $a$, or $2 \mathrm{mM}, b)$, with or without arginine $\left(100 \mu \mathrm{g} \mathrm{ml}^{-1}\right)$ and/or uracil $\left(50 \mu \mathrm{g} \mathrm{ml}^{-1}\right)$ was added to the cultures when the $\mathrm{OD}_{575}$ reached $0 \cdot 2$ (arrows). $\mathrm{OD}_{575}$ was monitored for a further $150 \mathrm{~min}$. The corresponding doubling times are shown in Table 3.

interaction with arginine $\left(100 \mu \mathrm{g} \mathrm{ml}^{-1}\right)$ and uracil $\left(50 \mu \mathrm{g} \mathrm{ml}^{-1}\right)$. The doubling time $(\mathrm{g})$ of strain BGM 023 in minimal medium was 54-55 min. Addition of $1 \mathrm{mM}-\mathrm{KNCO}$ to exponentially growing cultures moderately inhibited growth (Fig. $3 a$ ). After transient inhibition a stable $g$ value of $130 \mathrm{~min}$ could be observed. Arginine partially abolished cyanate inhibition $(g=78 \mathrm{~min})$. Uracil induced a progressive enhancement of inhibition; $30 \mathrm{~min}$ after addition of uracil and cyanate a stable $g$ value of 300 min could be observed. Addition of both uracil and arginine virtually abolished cyanate inhibition $(g=66 \mathrm{~min})$. In the presence of $2 \mathrm{mM}-\mathrm{KNCO}$, growth was strongly inhibited $(g=429 \mathrm{~min}$ ) (Fig. $3 b$ ). A partial restoration of growth could be obtained with arginine $(g=114 \mathrm{~min})$. Addition of both arginine and uracil allowed cells to grow at a higher rate $(g=85 \mathrm{~min})$. Uracil alone had little effect $(g=437 \mathrm{~min})$.

These results confirm that arginine reactivates cyanate-inhibited growth. Addition of uracil resulted in a rather complex set of interactions, depending on the concentration of cyanate. Moderate inhibition of growth by $1 \mathrm{~mm}-\mathrm{KNCO}$ was enhanced by uracil, but addition of both uracil and arginine resulted in a stronger reactivation of growth than did addition of arginine alone. These effects could be interpreted as the consequences of an inhibition by cyanate of both arginine and pyrimidine biosynthesis at the level of CPSase. Uracil added to cultures of $E$. coli is readily converted by UMP pyrophosphorylase (O'Donovan \& Neuhard, 1970; Piérard et al., 1972) into UMP, which effects feedback inhibition of CPSase (Piérard et al., 1965). Since UMP binds to the heavy subunit of CPSase (Trotta et al., 1971) and cyanate reacts with the light subunit (Anderson \& Carlson, 1975), a cumulative effect of UMP and cyanate on CPSase could result in a stronger inhibition of $\mathrm{CP}$ formation and in a shortage of $\mathrm{CP}$ for arginine biosynthesis.

\section{Derepression of ACTase, OCTase and CPSase in the presence of $1 \mathrm{mM}$ cyanate}

Further evidence supporting the above hypothesis was obtained by estimation of these enzyme activities after addition of $1 \mathrm{~mm}-\mathrm{KNCO}$ to exponentially growing cultures of BGM 023 . Addition of $1 \mathrm{~mm}-\mathrm{KNCO}$ resulted in derepression of OCTase and ACTase: $2 \mathrm{~h}$ after the 


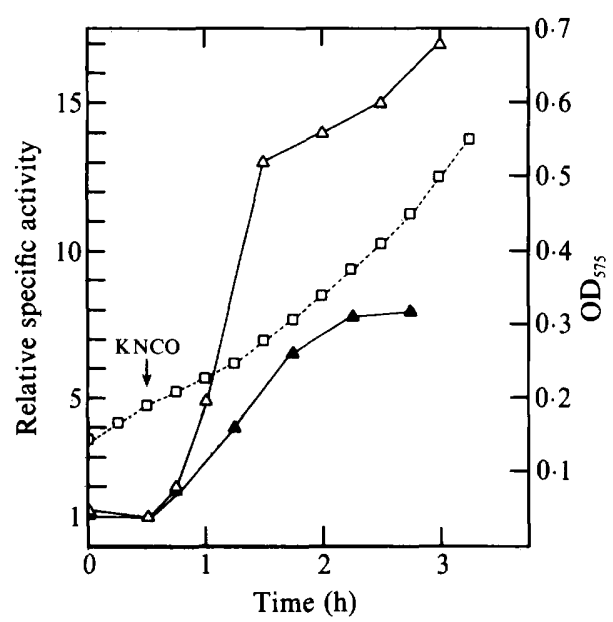

Fig. 4. Derepression of OCTase and ACTase induced by $1 \mathrm{mM}-\mathrm{KNCO}$ in strain BGM 023. An overnight culture was subcultured in minimal medium as described in Methods, and $1 \mathrm{mM}-\mathrm{KNCO}$ was added when the $\mathrm{OD}_{575}$ reached $0 \cdot 2$ (arrow). Samples were withdrawn at various times, treated with toluene for $20 \mathrm{~min}$ at $37^{\circ} \mathrm{C}$, and OCTase and ACTase specific activities were measured as described in Methods. The specific activities are expressed relative to the values at the beginning of the experiment. The specific activities of OCT ase and ACTase were initially 80 and 6.5 units $\mathrm{mg}^{-1}$, respectively; they had 600 and 110 units $\mathrm{mg}^{-1}$, respectively, at the end of the experiment. $\Delta$, OCTase; $\triangle$, ACTase; $\square$, $\mathrm{OD}_{575}$.

Table 2. Specific activities [ $\mu \mathrm{mol} \mathrm{h}^{-1}(\mathrm{mg} \text { protein })^{-1}$ ] of OCTase, ACTase and CPSase in strain $B G M 023$ and derivatives

$\begin{array}{lccc}\text { Strain (relevant genotype) } & \text { OCTase } & \text { CPSase } & \text { ACTase } \\ \text { BGM 023 (cnt3) } & 80 & 0.65 & 6 \cdot 5 \\ \text { BGM 171 (cnt3 } \operatorname{argR}) & 1520 & 1 \cdot 50 & \text { ND } \\ \left.\text { BGM 186 (cnt3 carB8/pMC40 } c a r A B^{+}\right) & 150 & 8 \cdot 35 & \text { ND } \\ \left.\text { BGM 209 (cnt } 3 \text { carB8)(Cit }{ }^{4 t}\right) & 720 & \text { ND } & 135\end{array}$

ND, Not determined.

addition the specific activities had increased by factors of 7.5 and 17, respectively (Fig. 4). The assay of CPSase showed that this enzyme was also subject to derepression ( 1.3 units $\mathrm{mg}^{-1}$ vs 0.65 units $\mathrm{mg}^{-1} 1 \mathrm{~h}$ after cyanate addition). These results show that both pyrimidine and arginine biosynthetic pathways are inhibited by cyanate.

Decreased arginine requirement produced by argR mutation or CPSase amplification

Since the arginine requirement of strain BGM 023 in the presence of cyanate was probably caused by a decreased availability of $\mathrm{CP}$ for the reaction catalysed by OCTase, enhancement of CPSase or OCTase might reduce the cyanate inhibition of growth. In order to obtain isogenic strains with enhanced CPSase or OCTase activities, strain BGM 023 was genetically modified as described in Methods. Strain BGM 171 is an argR mutant of BGM 023 and strain BGM 186 is a $c a r B 8$ derivative of BGM 023 harbouring plasmid pMC40 $\left(\operatorname{car} A B^{+}\right)$. Specific activities of OCTase and CPSase in these strains are presented in Table 2. It should be noted that $\arg R$ mutation derepresses OCTase and, to a lesser extent, CPSase. This derepression can be accounted for by the participation of the arginine repressor in the repression of CPSase in wildtype strains (Piérard et al., 1976). On the other hand, amplification of CPSase in strain 
Table 3. Effect of cyanate, arginine and uracil on generation times of strain BGM 023 and derivatives

Overnight cultures in minimal medium were subcultured and diluted as described in Methods. KNCO $(1 \mathrm{mM}, a$, or $2 \mathrm{mM}, b)$, with or without arginine $\left(100 \mu \mathrm{g} \mathrm{ml}^{-1}\right)$ and/or uracil $\left(50 \mu \mathrm{g} \mathrm{ml}^{-1}\right)$ were added when the $\mathrm{OD}_{575}$ reached $0 \cdot 2$. The table shows the generation times of the different strains calculated from $\mathrm{OD}_{575}$. The values in parentheses show the generation times expressed relative to the generation time of a control culture without additions. See also Fig. 3.

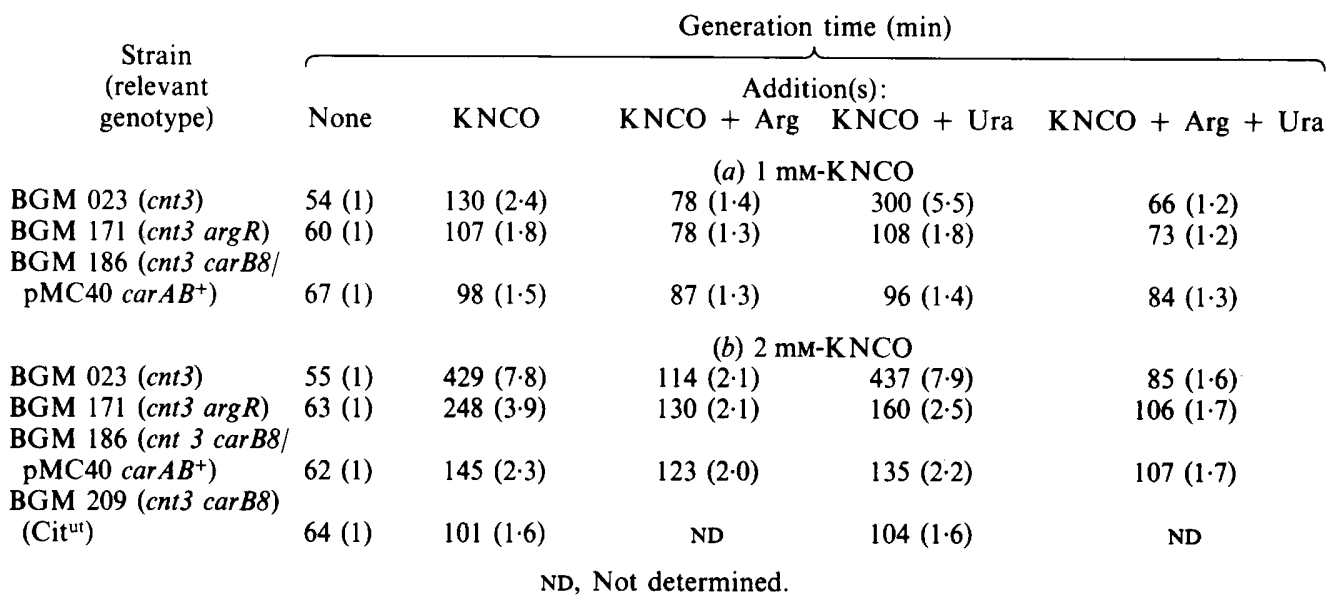

BGM 186 harbouring plasmid pMC40 $\left(\right.$ car $\left.A B^{+}\right)$slightly derepresses OCTase. Growth of these modified strains was tested in the presence of $1 \mathrm{~mm}$ - and $2 \mathrm{mM}-\mathrm{KNCO}$ and the influence of arginine and uracil was determined (Table 3). Firstly, both strains showed reduced sensitivity to cyanate. Secondly, the uracil sensitivity induced by $1 \mathrm{mM}-\mathrm{KNCO}$ in strain BGM 023 was no longer obtained in its isogenic derivatives BGM 171 and BGM 186. Some differences between these two strains can be pointed out. Uracil induced a marked growth reactivation of strain BGM $171(\arg R)$ in the presence of $2 \mathrm{mM}-\mathrm{KNCO}$; this behaviour may be interpreted as the consequence of a cyanate inhibition of pyrimidine biosynthesis. On the other hand strain BGM 186 was less sensitive to cyanate than strain BGM 171; thus it can be assumed that amplification of CPSase is more efficient than derepression of arginine biosynthesis in the reduction of cyanate sensitivity. Hence these results are in agreement with a specific inhibition of CPSase by cyanate in vivo.

\section{Absence of specific cyanate inhibition of pyrimidine biosynthesis in a mutant using citrulline as a source of $C P$}

carB8 strains are double auxotrophs for arginine and uracil. They possess no detectable CPSase activity (Mergeay et al., 1974) since they bear the extensive carB8 deletion which represents approximately $75 \%$ of the carB gene (Crabeel et al., 1980). Legrain et al. (1976) described the isolation of $c a r B 8$ strains able to grow on citrulline-supplemented medium. In such mutant strains CP is produced by phosphorolysis of citrulline, the reverse reaction of OCTase. Citrulline-utilizing strains show derepressed levels of OCTase and belong to various classes of mutants: $\arg G$ bradytrophs or strains in which synthesis of OCTase is specifically derepressed (Legrain et al., 1976). Strain BGM 180 (carB8 cnt3) was plated on minimal medium supplemented with L-citrulline $\left(2 \mathrm{mg} \mathrm{ml}^{-1}\right)$; spontaneous citrulline-utilizing mutants appeared at a frequency of $10^{-7}$. Specific activity of OCTase and ACTase in one of these mutants, BGM 209, was measured; Table 2 shows that the two enzyme activities were derepressed by factors of 9 and 21 , respectively. The effect of $2 \mathrm{mM}-\mathrm{KNCO}$ on the growth rate of BGM 209 was then tested. The results (Table $3 b$ ) showed that this strain has reduced sensitivity to cyanate and that the generation time is identical in the presence of $2 \mathrm{~mm}-\mathrm{KNCO}$ or $2 \mathrm{mM}-\mathrm{KNCO}+$ uracil 


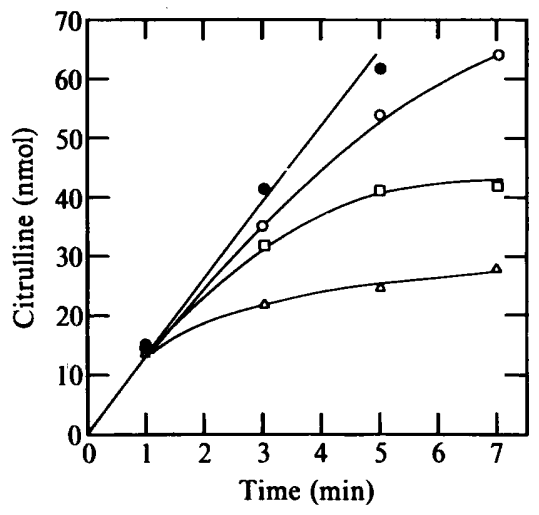

Fig. 5. Inhibition of CPSase by cyanate. A partially purified enzyme preparation from strain BGM 023 was used. The incubation medium was as described in Methods except that glutamine and ATP concentrations were $0.5 \mathrm{mM}$ and $6 \mathrm{mM}$, respectively. The reaction was initiated by addition of partially purified CPSase and stopped by TCA. Citrulline formed by coupling CPSase with added OCTase preparation was estimated by a modification of the method of Archibald (1944). $O$, Control without cyanate; O, 0.5 mM-KNCO; $\square, 1 \mathrm{mm-KNCO;} \triangle, 2 \mathrm{mm-KNCO}$.

$\left(50 \mu \mathrm{g} \mathrm{ml}^{-1}\right)$. This result suggests very strongly that the growth inhibition induced by cyanate in other strains is the consequence of an inhibition of CPSase.

\section{In vitro inhibition of CPSase activity by cyanate}

CPSase inhibition has been observed with $9 \mathrm{mM}-\mathrm{KNCO}$ (67\% inhibition) and $18 \mathrm{~mm}-\mathrm{KNCO}$ (86\% inhibition) in the presence of $5 \mathrm{~mm}$-glutamine (Anderson \& Carlson, 1975). Since these concentrations of cyanate are far above those used in this study it was of interest to know whether CPSase activity could be inhibited by cyanate in the $2 \mathrm{~mm}$ range. The effect of cyanate on CPSase activity was tested in the presence of $0.5 \mathrm{mM}$-glutamine, a concentration near the $K_{\mathrm{m}}$ value (Piérard \& Wiame, 1964) (Fig. 5). Cyanate inhibition proceeded gradually: 2 mM-KNCO inhibited CPSase by $50 \%$ within $3 \mathrm{~min}$. The relatively long-lasting pre-steady-state of cyanate inhibition is caused by the slowness of carbamoyl-CPSase formation and dissociation compared with the rapid equilibrium characterizing the glutamine-CPSase complex (Anderson \& Carlson, 1975). It is noteworthy that CPSase activity was assayed in the presence of $10 \mathrm{~mm}$ ornithine. Thus, the presence of this allosteric activator does not prevent CPSase inhibition.

\section{Kinetics of OCTase in the presence of cyanate}

The results presented in this study are consistent with CPSase inhibition by cyanate. However, they do not exclude the possibility of an inhibition of citrulline formation by OCTase as well. The saturation kinetics of OCTase activity in a cell-free extract of BGM 023 was followed as a function of ornithine in the absence or presence of $2 \mathrm{mM}-\mathrm{KNCO}$ and in the presence of $0 \cdot 1 \mathrm{mM}-\mathrm{CP}$ (non-saturating concentration). Cyanate did not modify the saturation of the enzyme by ornithine. This study was repeated in the presence of a saturating concentration of CP (2 mM); again no cyanate inhibition was observed.

It has been reported that zinc(II) inhibits OCTase activity and that saturation kinetics as a function of ornithine exhibits a positive cooperativity (Kuo et al., 1982). The above kinetic experiments were repeated in the presence of $0.4 \mathrm{~mm}$-zinc acetate (see Methods). Zinc did inhibit OCTase activity but, in our hands, the saturation kinetics remained strictly Michaelian; graphical analysis indicated a competition between zinc and ornithine. Cyanate ( $2 \mathrm{mM})$ did not afford an additional inhibition. 
Identical kinetic results were obtained with a partially purified preparation of OCTase [specific activity 12500 units (mg protein) ${ }^{-1}$ ] obtained from strain CSH 73 (carB8 $\arg R$ ). Thus it seems unlikely that OCTase is inhibited by cyanate in vivo.

\section{DISCUSSION}

The results presented here are consistent with a specific inhibition of CPSase by cyanate added to cultures of $E$. coli; this inhibition leads to an inhibition of arginine biosynthesis. Since cyanate-mediated inhibition leads to an arginine requirement, it is likely that a shortage of $C P$ is more critical for arginine than for pyrimidine biosynthesis.

Effects of cyanate on the kinetic properties of another enzyme of CP metabolism have been reported. Nelbach (1972) found that prolonged incubation of purified ACTase with high concentrations of CP led to a carbamoylated enzyme, still active but no longer regulated by CTP or ATP. She also reported that carbamoylation was effected by cyanate originating from dissociation of CP. We investigated this enzyme modification since a desensitization of ACTase might induce a metabolic deviation of $\mathrm{CP}$ towards pyrimidine biosynthesis and thus lead to a reduced availability of $\mathrm{CP}$ for arginine biosynthesis. A partially purified preparation of ACTase from BGM 023 was incubated for $30 \mathrm{~min}$ at $37^{\circ} \mathrm{C}$ with various concentrations of cyanate. Incubation with cyanate caused a slight decrease in $K_{0.5}$ for aspartate, and also decreased the allosteric activation by ATP and inhibition by CTP. Nonetheless these effects were obtained with relatively high concentrations of cyanate (e.g. $10 \mathrm{mM}$ ). Therefore it seems unlikely that such a modification of the kinetic properties of ACTase can actually induce by itself the observed requirement for arginine or citrulline.

The growth of Lactobacillus arabinosus and Streptococcus lactis is inhibited by carbamoyl compounds such as CP (Ravel et al., 1957) and $S$-carbamoylcysteine (Ravel et al., 1958); this growth inhibition can be reversed by arginine and citrulline but not by ornithine. CP and carbamoylcysteine are unstable compounds which dissociate readily in dilute solutions; the halflife of CP is $38 \mathrm{~min}$ at $37^{\circ} \mathrm{C}$ (Allen \& Jones, 1964) and this compound dissociates into inorganic phosphate and cyanate. Carbamoylcysteine is unstable at $\mathrm{pH}>6$ and dissociates into cysteine and cyanate with a half-life of approximately $92 \mathrm{~min}$ at $30^{\circ} \mathrm{C}$ (Stark, 1964). Besides a specific action of CP or carbamoyl-cysteine themselves on the micro-organisms, an action of cyanate originating from dissociation of these compounds was therefore highly probable. The long duration of these experiments $(27 \mathrm{~h})$ allowed a complete dissociation of these carbamoyl compounds, as discussed by Stark (1964) in the case of carbamoylcysteine. It is thus likely that in $L$. arabinosus and $S$. lactis, as in E. coli, CPSase is the specific target of cyanate.

Taking the above results into account, we propose that endogenous cyanate, arising from spontaneous dissociation of carbamoyl compounds, could participate in CPSase regulation. Among the carbamoyl compounds encountered in the metabolism of $E$. coli, citrulline and carbamoylaspartate are stable molecules, and urea (synthesized during growth of E. coli: Morris $\&$ Koffron, 1967) dissociates very slowly and to a limited extent (Marier \& Rose, 1964). Thus CP is probably the only carbamoyl compound which can give rise to endogenous cyanate. The existence of a pool of CP implies cyanate formation in vivo. On the other hand our observations showed that CP biosynthesis is a specific target of cyanate. We propose that CPSase is subject in vivo to a 'by-product' regulation mechanism in which cyanate originating from the dissociation of CP exerts a reversible inhibition of the enzyme. This inhibition would be essentially effective in the regulation of arginine biosynthesis. This regulation mechanism would provide the cell with an energy-saving device depending on cellular CP level, which would modulate the allosteric regulation of CPSase by UMP (inhibitor) (Piérard et al., 1965), ornithine (antagonistic activator) (Piérard, 1966), and purine nucleotides (allosteric activators) (Anderson $\&$ Meister, 1966). Direct evidence for the proposed mechanism will require a reliable and sensitive assay of endogenous cyanate in bacteria.

We wish to acknowledge Dr A. Piérard, Dr M. Crabeel and Dr N. Glansdorff for gifts of bacterial strains, and Dr M. Schwartz for a gift of bacteriophage Pl. Technical assistance from J. Bertrand and P. Bressolier was greatly appreciated. We thank Dr F. Nau for assistance in preparing the manuscript. 


\section{REFERENCES}

AbD el al., A., Kessler, D. P. \& Ingraham, J. L. (1969). Arginine auxotrophic phenotype resulting from a mutation in the pyrA gene of $E$. coli $\mathrm{B} / \mathrm{r}$. Journal of Bacteriology 97, 466-468.

AbD el al., A. T. H., Griego, E. \& INGraham, J. L. (1978). Arginine auxotrophic phenotype mutations in pyrA of Salmonella typhimurium: role of $\mathrm{N}$ acetylornithine in the maturation of mutant carbamyl phosphate synthetase. Journal of Bacteriology 134, 528-536.

Allen, C. M. \& Jones, M. E. (1964). Decomposition of carbamylphosphate in aqueous solutions. Biochemistry 3, 1238-1247.

ANDERson, P. M. \& Carlson, J. D. (1975). Reversible reaction of cyanate with a reactive sulfhydryl group at the glutamine binding site of carbamyl phosphate synthetase. Biochemistry 14, 3688-3694.

ANDERSON, P. M. \& Meister, A. (1966). Control of Escherichia coli carbamoylphosphate synthetase by purine and pyrimidine nucleotides. Biochemistry $\mathbf{5}$, 3164-3169.

Anderson, P. M., Wellner, V. P., Rosenthal, G. A. \& MeISTER, A. (1970). Carbamyl phosphate synthetase (Escherichia coli). Methods in Enzymology 17A, 235-243.

Anderson, P. M., Carlson, J. D., Rosenthal, G. A. \& MeISTER, A. (1973). Effect of potassium cyanate on the catalytic activities of carbamoylphosphate synthetase. Biochemical and Biophysical Research Communications 55, 246-252.

ARCHIBALD, R. M. (1944). Determination of citrulline and allantoine and demonstration of citrulline in blood plasma. Journal of Biological Chemistry 156, 121-142.

Bertini, I., Borghi, E., Luchinat, C. \& ScozzafaVa, A. (1981). Binding sites of anions in superoxide dismutase. Journal of the American Chemical Society 103, 7779-7783.

Bertini, L., Lanini, G. Luchinat, C. \& Monnani, R. (1985). Investigations of cobalt(II)-substituted carboxypeptidase $\mathrm{A}$ interacting with azide and cyanate ions. Inorganica chimica acta 107, 153-157.

Bolivar, F., Galvan, M. \& Martuscelli, J. (1976). Biochemical and genetic characterization of a carbamylphosphate synthetase mutant of Escherichia coli K12. Journal of General Microbiology 94, 142-148.

Bussey, L. B. \& Ingraham, J. L. (1982). A regulatory gene (use) affecting the expression of pyrA and certain other pyrimidine genes. Journal of Bacteriology 151, 144-152.

Chollet, R. \& Anderson, L. L. (1978). Cyanate modification of essential lysyl residues in the catalytic subunits of tobacco ribulose diphosphate carboxylase. Biochimica et biophysica acta 525, 455467.

Crabeel, M., Charlier, D., Weyens, G., Feller, A., PiÉrard, A. \& GlansdorfF, N. (1980). Use of gene cloning to determine polarity of an operon: genes car AB of Escherichia coli. Journal of Bacteriology 143, 921-925.

Dustin, P. (1947). Some new aspects of mitotic poisoning. Nature, London 159, 794-797.
ENGBerg, P. \& LindsKog, S. (1984). Effect of $\mathrm{pH}$ and inhibitors on cobalt II carbonic anhydrase III from bovine skeletal muscle. FEBS Letters 170, 326-330.

Forster, D. \& GoOdGaME, D. M. L. (1965). Vibrational spectra of pseudo-halide complexes. II. Planar and octahedral isocyanate complexes. Journal of the Chemical Society, 1286-1289.

Gerhart, J. C. \& Pardee, A. B. (1962). The enzymology of control by feed-back inhibition. Journal of Biological Chemistry 237, 891-896.

Guilloton, M. \& Karst, F. (1985). A spectrophotometric determination of cyanate using reaction with 2-aminobenzoic acid. Analytical Biochemistry 149, 291-295.

GuIlloton, M. \& KARST, F. (1987). Isolation and characterization of Escherichia coli mutants lacking inducible cyanase. Journal of General Microbiology 133, 645-653.

Kuo, L. C., Lipscomb, W. N. \& Kantrowitz, E. R. (1982). Zn(II)-induced cooperativity of Escherichia coli ornithine transcarbamoylase. Proceedings of the National Academy of Sciences of the United States of America 79, 2250-2254.

Legrain, C. \& Stalon, V. (1976). Ornithine carbamoyltransferase from Escherichia coli W. European Journal of Biochemistry 63, 289-301.

Legrain, C., Stalon, V., Glandsorff, N., Gigot, D., PiÉRARD, A. \& Crabeel, M. (1976). Structural and regulatory mutations allowing utilization of citrulline or carbamoylaspartate as a source of carbamoylphosphate in Escherichia coli K 12. Journal of Bacteriology 128, 39-48.

Lissens, W., Cunnin, R., Kelker, N., Glansdorff, N. \& PiÉRaRd, A. (1980). In vitro synthesis of Escherichia coli carbamoylphosphate synthetase: evidence for participation of the arginine repressor in cumulative repression. Journal of Bacteriology 141 , 58-66.

MAas, W. K. (1961). Studies on the repression of arginine biosynthesis in Escherichia coli. Cold Spring Harbor Symposia on Quantitative Biology 26, 183191.

Maniatis, T., Fritsch, E. F. \& Sambrook, J. (1982). Molecular Cloning, a Laboratory Manual. Cold Spring Harbor, NY: Cold Spring Harbor Laboratory.

MARIER, J. R. \& Rose, D. (1964). Determination of cyanate and a study of its accumulation in aqueous solutions of urea. Analytical Biochemistry 7, 304-314.

Mergeay, M., Gigot, D., Beckmann, J., GlansDORFF, N. \& PIÉRARD, A. (1974). Physiology and genetics of carbamoylphosphate synthesis in Escherichia coli K12. Molecular and General Genetics 133, 299-316.

MILleR, J. H. (1972). Experiments in Molecular Genetics. Cold Spring Harbor, NY: Cold Spring Harbor Laboratory.

MorRIS, D. R. \& Koffron, K. L. (1967). Urea production and putrescine biosynthesis by Escherichia coli. Journal of Bacteriology 94, 1516-1519.

NeLBaCH, M. E. (1972). Studies on the association of subunits in aspartate transcarbamylase from Escherichia coli. PhD Thesis, University of California at Berkeley. 
Neuhard, J., Jensen, K. F. \& Stauning, E. (1982). Salmonella typhimurium mutants with altered expression of pyrA due to change in RNA polymerase. EMBO Journal 1, 1141-1145.

NovicK, R. P. \& MaAs, W. K. (1961). Control by endogenously synthesized arginine of the formation of ornithine transcarbamylase in Escherichia coli. Journal of Bacteriology 81, 236-240.

O'Donovan, G. A. \& Neuhard, J. (1970). Pyrimidine metabolism in microorganisms. Bacteriological Reviews 34, 278-343.

Pastra-Landis, S. C., Foote, J. \& Kantrowitz, E. R. (1981). An improved colorimetric assay for aspartate and ornithine transcarbamylases. Analytical Biochemistry 118, 358-363.

PIÉRARD, A.(1966). Control of the activity of Escherichia coli carbamoylphosphate synthase by antagonistic allosteric effectors. Science 154, 1572-1573.

PiÉrard, A. \& Wiame, J. M. (1964). Regulation and mutation affecting a glutamine dependent formation of carbamylphosphate in Escherichia coli. Biochemical and Biophysical Research Communications 15, 7681.

Piérard, A., Glansdorff, N., Mergeay, M. \& WIAME, J. M. (1965). Control of the biosynthesis of carbamoylphosphate in Escherichia coli. Journal of Molecular Biology 14, 23-26.

Piérard, A., GlansdorfF, N. \& YashPhe, J. (1972). Mutations affecting uridine monophosphate phosphorylase or the $\arg R$ gene in Escherichia coli. Molecular and General Genetics 118, 235-245.

Piérard, A., Glansdorff, N., Gigot, D., Crabeel, M., HalleuX, P. \& ThIRY, L. (1976). Repression of Escherichia coli carbamoylphosphate synthase. Relationships with enzyme synthesis in the arginine and pyrimidine pathways. Journal of Bacteriology 127, 291-301.

PrescotT, L. M. \& Jones, M. E. (1969). Modified methods for the determination of carbamyl aspartate. Analytical Biochemistry 32, 408-419.
Ravel, J. M., Estes, J. M., Mollenhauer, B. F. \& SHIVE, W. (1957). Some inhibitory properties of carbamylphosphate. Journal of Biological Chemistry 231, 93-99.

Ravel, J. M., McCord, T. J., Skinner, C. G. \& Shive, W. (1958). S-Carbamyl-L-cysteine, an inhibitory aminoacid analogue. Journal of Biological Chemistry 232, 159-168.

SchÜTZ, F. (1949). Cyanate. Experientia 5, 133-172.

Sluyterman, L. A. A. (1967). Reversible inactivation of papain by cyanate. Biochimica et biophysica acta 135, 439-449.

STARK, G. R. (1964). On the reversible reaction of cyanate with sulphydryl groups and the determination of the $\mathrm{NH}_{2}$ terminal cysteine and cystine in proteins. Journal of Biological Chemistry 239, 14111414.

STARK, G. R. (1965). Reactions of cyanate with functional groups of proteins. III. Reactions with amino and carboxyl groups. Biochemistry 4, 10301036.

TAussig, A. (1960). Effect of carbamylphosphate and cyanate on Escherichia coli. Canadian Journal of Microbiology 6, 619-629.

Trotta, P. P., Burt, M. E., Haschemeyer, R. H. \& Meister, A. (1971). Reversible dissociation of carbamylphosphate synthetase into a regulated synthesis subunit and a subunit required for glutamine utilisation. Proceedings of the National Academy of Sciences of the United States of America 68, 25992603.

Veronese, F. M., Pisklewicz, D. \& Smith, E. L. (1972). Inactivation of bovine glutamate dehydrogenase by carbamylphosphate and cyanate. Journal of Biological Chemistry 247, 754-759.

Williams, A. \& JeNCKs, W. P. (1974). Urea synthesis from amines and cyanic acid. Kinetic evidence for a zwitterionic intermediate. Journal of the Chemical Society, Perkin Transactions 2, 15, 1753-1759. 